\title{
Intoxicación aguda por Talio
}

Drs. Jame Condero T * Y Patricio Olivos M.

Pese a ser el talio uno de los metales más tóxicos, aún se emplea ampliamente como raticida en nuestro pais, facilitando el acceso del tóxico al niño con la consecuente intoxicación. Todos los efectos del talio pueden ser catălogados como tóxicos. Se absorbe también por la piel, al aplicárselo como depilatorio ${ }^{3}$. El talio se distribuye por todo el organismo fijándose en los tejidos. Se excreta por el riñón y el intestino durante varias semanas e incluso meses ${ }^{2}$.

El cuadro clínico de una intoxicación aguda por talio es insidioso, aun en las formas mortales, Io que impide un tratamiento efectivo en las primeras horas. En las primeras 24 horas puede haber náuseas y vómitos que son ocasionalmente hemorrágicos, dolores abdominales de tipo cólico; esto desaparece y se agregan convulsiones, coma y manifestaciones de un compromiso tubular renal severo, 3 a 14 días más tarde. La polineuritis grave puede manilestarse a veces ya a las 24 horas de la ingesta de talio y progresa rápidamente. Estos pacientes generalmente fallecen.

En casos menos graves, después del compromiso gastrointestinal inicial, hay un compromiso insidioso con constipación, calambres abdominales, dolor retroesternal, dolor en piernas, taquicardia $y$, finalmente, polineuritis, demencia y ataxia importante. Todo esto va tn aumento y comienza a regresar al cabo de varias semanas, aunque la polineuritis puede demorar, en ocasiones, años en recuperarse plenamente. Después de 2 a 3 semanas, se aprecia una piel seca con anhidrosis, estriación transversa de las uñas (banda ungeal de Mees) a consecuencia de un trastorno de crecimiento de éstas y especialmente una caída espontánea de la cabellera, pudiendo llegar en 3 sema-

-Hospital 1,uis Calvo Mackenna. nas a la alopecia total. Se afecta también el pelo de la axila, pubis y parte lateral de las (ejas ${ }^{5}$.

En intoxicaciones crónicas, la neuritis retrobulbar es frecuente $y$ el daño puede ser permanente; también se describe necrosis central de hígado.

El talio se determina en orina y deposición. Al empapar en orina un asa de platino y acercarla a un mechero de Bunsen la llama adqwere un color verde esmeralda ${ }^{2}$.

\section{CASOS CLINICOS}

\section{CASO $\mathrm{N}^{\mathrm{O}} 1$}

Escolar de 6 años, que el 12 de febreno de 1975 ingiere, en forma accidental, concentrado puro de sulfato de talio; una hora más tarde concurre a Servicio de Urgencia donde se practica lavado gástrico. Un dia después presenta vómitos y dolor abdominal durante 24 horas. Posteriormente comienza en forma insidiosa con somnolencia, apatía y dificultad para hablar. Al cuarto día ingresa al Hospital Sótero del Rio, encontrándose en sopor superficial, con disartria y pareșia facial bilateral, disminución de fuerzas en extremidades con hipotonia e hiporreflexia osicotendínea $y$ ataxia.

Se hace el diagnóstico de intoxicación aguda por calio. El compromiso de consciencia se acentúa rápidamente y aparece compramiso de musculatura respiratoria presentando respiración muy supericial.

A] sexto día se traslada al Hospital Calvo Mackenna donde ingresa inconsriente. Pulso $120 x^{*}$, respiración $16 x^{\prime}$ superficial, presión arterial $110 / 80 \quad i^{\circ} 36^{\circ} 2$ axilar, con paresia facial; el murmulio vesicular muy disminuido, hipotanía e hiporreflexia en las 4 extremidades. Se diagnostica intoxicación aguda por talio, polineuritis tóxica $e$ insuficiencia respiratoria. Se efectúa traqueostomia $y$ se conecia a respirador mecánico. Al séptimo dia sólo moviliza escasamente hombro y codo. Hay mala ventilación en las hases pulmonares. Se mantiene sin conexión ambiental. pero lo interpretamos como por falta de expresión por su parátisis. Los exámenes de laboratorio revelan una uremia de $1,47 \mathrm{gr} / 11$ y en la orina una albuminuria de $0,40 \mathrm{gr} / 1 \mathrm{t}$ y hematuria escasa. Lud diuresis es escasa. Se deja con regimen sin proteinas y con restricción de liquidos. 
En la tarde de ese dia aparecen atelectasias masjuas que se logran reducir con hiperpresión $\gamma$ kinesiterapia respiratoria. No reacciona a los estímulos dolorosos y no tiene ningún movimiento; la presión arterial ya en descenso. Se efectúa una transfusión de $180 \mathrm{ml}$ de sangre. Al octavo día se encuentra frío, sin pulsos periféricos, con midriasis paralítica, cianosis importante, atelectasias pulmonares bilatemies y anuria, falleciendo a media mañana.

Las muestras enviadas al Instituto Medico l.egal informan en sangre: intensamente positiva a talio, $y$ en orina. débilmente positiva a talio.

\section{CASO $\mathrm{N}^{\circ} 2$}

Preescolar de 5 años (hermana del caso $N^{\circ} 1$ ), que el 12 de febrero de 1975 ingiere, en forma arcidental, concentrado puro de sulfato de talio; una hora mas tande concurre a Ser. vicio de Urigencia donde se practica lavado gástrico. Al dia siguiente presenta vómitos y dolor abdominal durante 24 horas. En los dias sucesivos presenza decaimiento, sed intensa, inapetencia, falta de fuerzas y caida del cabello. Al octayo dia ingresa al Hospital Sótero del Rio, donde se encuentra consciente, cooperadora, con paresia facial. disminurión global de fuerzas y reflejos osteotendineos cambiér disminuidns. Las pruebas de coordinacion están levemente alteradas

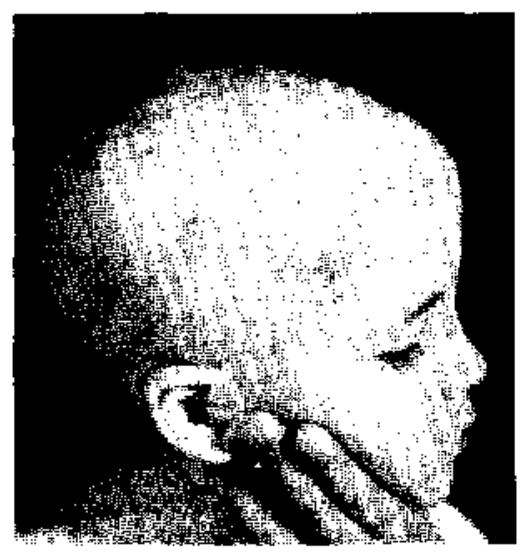

Se hace el diagnóstico de intoxicación aguda por talio. Se trata con cloruno de potasio oral que debe suspenderse por intolerancia gástrica a las 24 horas y penicilina sódica 7.000 .000 de unidades endovenosa cada 4 horas. Permanece en iguales condiciones hasta el día 11 de evolución apareciendo luego en forma progresiva dismetría, ataxia, alteración de conducta, irritabilidad y pérdida de consciencia transitoria, decidiéndose el día 13 suspender la penicilina sódica y agregar ditizorta $20 \mathrm{mg} \times \mathbf{~ k g}$.

EJ dia 14 de evolución aparece compromiso respiratorin. por to que se traslada al Hospital Calyo Mackenna. Al examen se encuentra lúcida, marcha temblotosa, caída de cabello, presión anterial $120 / 95$ y un pulso de $140 \times$ respiración de $24 \times$ ', con buena ventilación pulmonar. Las exrremidades están hipolónicas y los reflejos osteotendíneos abolidos. Se mantiene la ditizona hasta completar 5 dias pero disminuyendo la dosis a $10 \mathrm{mg}$ por $\mathrm{kg}$ al día.
Las muestras enviadas al Instituto Médion Legal informan en sangre intensamente positiva a talio y en orina negativo. Protnombina $15 \%$, Ćremia 0,46 gr/11, transaminasas glutámíc y pirúvica 78 U.K., L.C.R. normal y el examen de orina revela una hematuria escasa.

Persiste la hipenensión, el compromiso cerebeloso se va arentuando y también el compromiso motor especialmente en extremidades inferiores; presenta, además, episcudios de desconexión y llanto seguidos de sueño que duran una hora, después de lo cual recupera contacto ambiental.

A $\operatorname{los} 25$ días se encuentra sin hipertensión, se conecta con el examinador, responde a ordenes simples, la marcha es muy dificultosa por falta de fuerzas, hay gran hipatonía e hiporteflexsa esperiahmente de extremidades inferiores. El fondo de ojo es normal. A los 30 dias se encuentra con alopecía total (Foto 1) y desde el punto de vista psíquico está mejor, sin embargo hay mayor compromiso cerebeloso y motor. No puede sentarse, hay gran temblor y falta de fuer. zas. En las extremidades supenores los neflejos están muy disminudos. en las infenores comienzan a aparecer. En este momento la uremia es de $0,32 \mathrm{gr} / \mathrm{lt}$., las transaminasas glutámico pirúvica 19 U.K., el examen de orina es normal y el EEG revela signos de surrimiento cartical asi como también de estructuras subcorticales. A los 40 dias es capaz de sentarse sola en la cama, realiza movimientos finos con las manos, las furzas van mejorando, los reflejos osteotendíneos se obtienes más fácilmente y es capaz de dar algunos pasos.

Los resultados de la eliminación de talio en nrina* revelaron:

\begin{tabular}{cc} 
Días de evolución & $\begin{array}{c}\text { Concentractón de talio en } \\
\text { onna }\end{array}$ \\
\hline 9 & $17,7 \mathrm{mg} / 1$ \\
19 & $14,4 \mathrm{rng} / 1$ \\
20 & $12,9 \mathrm{mg} / 1$ \\
32 & $3,5 \mathrm{rng} / 1$ \\
36 & $1,2 \mathrm{rng} / 1$ \\
40 & $0,3 \mathrm{mg} / 1$ \\
\hline
\end{tabular}

Se da de alta en buenas condiciones a les 43 dias.

\section{CASO $\mathrm{N}^{\circ}$}

Lactante de 1 año 3 meses, que el 9 de octubre de 1973 acude al Hospital de Buin por presentar crisis convulsivas dando el antecedente de probable ingesta de maíz que se habría desinfectado con insecticida órgano fosforado. En Buin se le administra fenobartbital sódico $75 \mathrm{mg}$ im., diaxepan $7,5 \mathrm{mg}$ im., pentobarbital $500 \mathrm{mg} \mathrm{ev}$, PAM $500 \mathrm{mg}$ ev. y atropina $2 \mathrm{mg}$ ev.; por mantener convulsiones se Iraslada al Hospital Calvo Mackenna. Al ingreso presenta convulsiones tónico clónicas generalizadas, hay midriasis, taquicardia de 200 por min y rubicundez facial. Se indica $1 \mathrm{mg}$ de alropina endovenoso, hace paro respiratorio del cual sale con uso de respirador mecánico; vuelve a presentar convul-

\footnotetext{
- ixeterminaciones efectuadas en Laboratorio de Higiene Industria] SNS
} 
siones administrándose diazepan 7 mg endovenoso, continuándose con $0,3 \mathrm{mg}$ de atropina endovenoso cada $20^{\prime}$ EI LCR es normal. Reaparecen las convulsiones indicándose nuevas dosis de diazepan. A las 12 horas de ingreso se revalúa el caso pensando que se trata de una encefalitis, cambiándose tratamiento a manitọl y corticoides.

A los $\mathbf{4}$ dias se mantiene inconsciente, aunque racciona a los estímulos dolorsos, hay gran hipotonia, $y$ los reflejos osteotendíneos están disminuidos. A los 6 dias de evolución se encuentra consciente aunque sin mayor interés por el medio. A los 8 dias tiende a coger objetos, pero no juega con ellos, no se sienta ni se para, y llama la atención la caida del cabello planteándose la posibilidad de una intoxicacación por takio. Se obriene el antecedente de la existencia en el hogar del raticida Celio $(0,74 \mathrm{gr}$ de sulfato de talio) y que estaba al alcance de la paciente. Se suspende corticoides. A los 12 días jucga con objetos, aún no se sienta y presenta una zona de alopecia. A los 16 días el EEG demuestra una lentitud bilateral que indica un sufrimieno encefálico difuso. A los 25 días de evolución se encuentra en buenas condiciones, jucga, canıa, intenta dar pasos. Es dada de alta a los 30 dias

En control a los 50 días de evolución, camina bien, se comienza a notar salida de cabello nuevo y el examen neurülogice es normal

\section{TRATAMIENTO}

El tratamiento inmediato debe incluir el lavado gástrico con una solución de yoduro de sodio a) $1 \%$ para precipitar el talio no absorbido, formando yoduro de talio insoluble. La administración oral de sales de yoduro de potasio para impedir la reabsorción debe ser prolongada, ya que las deposiciones son la principal vía natural de eliminación de talio, y el talio se sigue eliminando durante un largo periodo por la vía digestiva.

Recientemente se han comunicado excelentes resultados aun en intoxicaciones no inmediatas con administración de azul de prusia (cianoferrato II de potasio férrico), en que se reemplaza el ion $\mathbf{K}$ por talio en la molécula del azul de prusia, haciéndolo menos absorbible ${ }^{6}$. Barbier comunica, en 1974,15 casos tratados con azul de prusia con buen resultado, empleó dosis entre 88 y $416 \mathrm{mg} / \mathrm{kg}$ por dia por vía oral (con una media de $285 \mathrm{mg} / \mathrm{kg}$ ); ya que la eliminación fecal es aún importante cuando la eliminación urinaria ha disminuido a $0,5 \mathrm{mg}$ en 24 horas, recomienda la administración del azul de prusia por un largo período ${ }^{1}$. También debe tratarse la constipación.
El uso de agentes quelantes como el BAL, CaEDTA y d-penicilarnina han sido ensayados sin éxito tanto en animales como en el hombre, además estos compuestos tienen efectos tóxicos. El BAL produce taquicardia hipertensión, parestesias y náuseas. El CaEDTA produce necrosis tubular renal, y la d-penicilamina síndrome nefrótico, trastomos de coagulación, leucopenia y neutropenis, rash eritematoso y alteraciones del metabolismo del colágeno ${ }^{2}$.

Se ha planteado tambièn que los agentes quelantes podrian facilitar la entrada de talio al sistema nervioso".

La ditizona y el dietilditiocarbamato son efectivos en animales, pero son altamente tóxicos habiéndose empleado la ditizona para producir diabetes aloxánica; causa también daño ocular, por lo tanto su uso se justificaria sólo en casos de intoxicados con riesgo de vida ${ }^{2}$ ".

Se ha recomendado el uso de diálisis peritoneal para prevenir un nuevo ciclo de la droga al intestino. Con esta técnica se han recuperado cantidades apreciables de talio en el liquido de la diálisis. La hemodiálisis no tendría valor ${ }^{6}$.

\section{CONGLUSIONES}

Se presentan 3 casos de intoxicación aguda por talio. Se analizan las medidas actuales del tratamiento de esta intoxicación, destacando el uso del lavado gástrico con solución de yoduro de sodio al $1 \%$ para evitar la absorción si la intoxicación es reciente y para facilitar la eliminación de la droga absorbida, y dado que ésta se hace fundamentalmente por la vía digestiva se recomienda la administración por vía oral de yoduro de potasio o azul de prusia, durante un tiempo prolongado tratando, además, la constipación. A pesar que éstas medidas no las empleamos en nuestros casos, ya que tuvimos información de estas terapéuticas con posterioridad, 2 de ellos evolucionaron a una mejoria total.

En caso de una polineuritis deberá vigilarse la mecánica ventilatoria por el riesgo de una insuficiencia respiratoria; también deberá controlarse la función renal por el riesgo de una insuficiencia renal, y la función hepática. 
Hacemos esta presentación con la intención de comunicar el cuadro clínico y especial. mente las medidas rerapécuticas utilizables en esta intoxicación

\section{AC;RADECIMIENTOS}

Se agradece al señor Juan Iabarca Villarroel, quínico del Laboratorio de Higien: Industrial dependiente del Ins. tiruto de Hiejene del 'Trabajo y Comaminatión Simostirico (Santo Domingo 2398), por su conperatión en lat ils. reminación de la concenl ración de talios en orina.

\section{REFERENCIAS}

Barbier, F. Lancet 2, 965, 1974.

2 Chisolm, J. Ped. Clin. of N.A. 17:591, 1970.

3 Goodman, L.; Gilman, A. The Pharmacological Basis of Therapeutics. The Mac Millan Company, $990,1955$.

1 Lecannelier, S. Comunicación personal, 1975.

'Scheid, W. Tratado de Neurologia. Editorial Alhambra, 788, 1969.

5 Thatlium. Lancet 2, 564, 1974. 